\title{
Alkylphenol Polyethoxylate Derivatives in Groundwater and Blood Samples Collected from Pig Herds in Taiwan
}

\author{
Tai-Shun CHIU ${ }^{1) \#, ~ C h i-Y i n g ~ H S I E H ~}{ }^{2) \#, ~ C h a n g-L i n g ~ M I A W ~}{ }^{3)}$, Chao-Nan LIN ${ }^{1)}$, Tsung-Chou CHANG ${ }^{1)}$, Chia-Hung YEN ${ }^{4)}$ \\ and Ming-Tang $\mathrm{CHIOU}^{1) *}$ \\ ${ }^{1)}$ Department of Veterinary Medicine, National Pingtung University of Science and Technology, Nei-pu, Pingtung 912, Taiwan, ROC \\ ${ }^{2)}$ Department of Environmental Science and Engineering, National Pingtung University of Science and Technology, Nei-pu, Pingtung 912 , \\ Taiwan, $R O C$ \\ ${ }^{3)}$ Department of Nursing, Tajen University, Yan-pu, Pingtung 907, Taiwan, ROC \\ 4) Department of Life Science, National Pingtung University of Science and Technology, Nei-pu, Pingtung 912, Taiwan, ROC
}

(Received 11 February 2014/Accepted 14 March 2014/Published online in J-STAGE 1 April 2014)

ABSTRACT: Alkylphenol polyethoxylate (APEO) derivatives, such as nonylphenol monoethoxylate $\left(\mathrm{NP}_{1} \mathrm{EO}\right)$, nonylphenol diethoxylate $\left(\mathrm{NP}_{2} \mathrm{EO}\right)$, nonylphenol (NP) and octylphenol (OP), have been detected in the surface water, sediment, food and groundwater of numerous countries. Because groundwater is the main source of water for pig herds, the aim of this study was to measure the concentrations of APEO derivatives in groundwater and blood samples that were collected from pig herds raised near the Wuluo River in Southern Taiwan. The mean concentrations of NP, OP, $\mathrm{NP}_{1} \mathrm{EO}$ and $\mathrm{NP}_{2} \mathrm{EO}$ in the groundwater supply for 10 pig herds were $0.04 \mu \mathrm{g} / l, 0.26 \pm 0.23 \mu \mathrm{g} / l, 0.74 \pm 0.69 \mu \mathrm{g} / l$ and $0.17 \pm 0.22 \mu \mathrm{g} / l$, respectively. NP was detected in all blood samples collected from 5 of the 10 pig herds. The highest concentrations detected in the blood samples collected from six-week-old piglets and sows were $12.00 \mu \mathrm{g} / \mathrm{l}$ and $56.94 \mu \mathrm{g} / l$, respectively. Blood samples from 4 of the 5 herds showed OP contamination. The highest OP concentrations detected in 6-week-old piglets and sows were $275.58 \mu \mathrm{g} / \mathrm{l}$ and $566.32 \mu \mathrm{g} / l$, respectively. These results indicate that APEO derivatives accumulated in the groundwater supply and the bloodstreams of the pigs. KEY WORDS: blood, groundwater, nonylphenol, octylphenol, swine.

doi: 10.1292/jvms.14-0070; J. Vet. Med. Sci. 76(7): 971-975, 2014

In recent decades, alkylphenol polyethoxylates (APEOs) have been used worldwide in numerous industrial and agricultural products, including detergents, paints, herbicides, wetting agents, cosmetics and pesticides. Nonylphenol polyethoxylates (NPEOs) constitute approximately 80\% of APEOs, and octylphenol polyethoxylates (OPEOs) constitute the remaining $20 \%$ [14]. Almost $60 \%$ of APEOs are discharged into aquatic environments through sewage treatment plant and industrial effluents [9]. APEOs are degraded by bacteria under anaerobic conditions and converted into shorter-chain alkylphenols, which exhibit greater liposolubility. APEO degradation products include nonylphenol monoethoxylate $\left(\mathrm{NP}_{1} \mathrm{EO}\right)$, nonylphenol diethoxylate $\left(\mathrm{NP}_{2} \mathrm{EO}\right)$, nonylphenol (NP) and octylphenol (OP) [3]. These substances have been detected in various food products, groundwater and rivers in many countries, including Taiwan $[1,4,8]$.

APEO derivatives can accumulate in the body through the intake of contaminated food and water [2]. Endocrine-

*Correspondence to: Chiou, M.-T., Department of Veterinary Medicine, College of Veterinary Medicine, National Pingtung University of Science and Technology, No. 1, Hsueh-Fu Road, Nei-pu, Pingtung 912, Taiwan, ROC.

e-mail:mtchiou@mail.npust.edu.tw

\#Equal Contributors.

C 2014 The Japanese Society of Veterinary Science

This is an open-access article distributed under the terms of the Creative Commons Attribution Non-Commercial No Derivatives (by-nc-nd) License $<$ http://creativecommons.org/licenses/by-nc-nd/3.0/>. disrupting chemicals, such as NP and OP, can mimic, antagonize, enhance or inhibit endogenous hormones and can act as pseudoestrogens in vivo $[5,11]$. A previous study reported that male fish exposed to NP and OP exhibited decreased reproductive capacity and vitellogenin synthesis, which resulted in yolk degeneration in piscine oocytes [14]. In addition, dogs treated with APEO mixtures exhibited symptoms of cardiotoxicity [12]. It has been determined that APEOs can reduce cytokines secretion and immunoglobulin synthesis in vitro $[5,17]$.

Because groundwater is the main source of drinking water for pig herds in Taiwan, a thorough investigation of endocrine disruptors, such as APEO derivative concentrations in pig blood and the groundwater supply on pig farms, is required. The aim of this study was to determine the prevalence and concentrations of APEO derivatives in the groundwater supply for 10 pig herds located along the Wuluo River, which is one of the tributaries of the Kao-Ping River. The Kao-Ping River is the second longest river in Taiwan and the main source of water for the surrounding area. Blood samples were collected from piglets and sows in 5 of the 10 herds; the samples were analyzed for NP and OP.

\section{MATERIALS AND METHODS}

Chemicals: The 4-n-nonylphenol and 4-octylphenol stocks were purchased from Aldrich Chemical Co. (Milwaukee, WI, U.S.A.). The 4-nonylphenol-monoethoxylate $\left(\mathrm{NP}_{1} \mathrm{EO}\right)$ and 4-nonylphenol-diethoxylate $\left(\mathrm{NP}_{2} \mathrm{EO}\right)$ stocks were purchased from Hayashi Pure Chemical (Osaka, Japan). All 


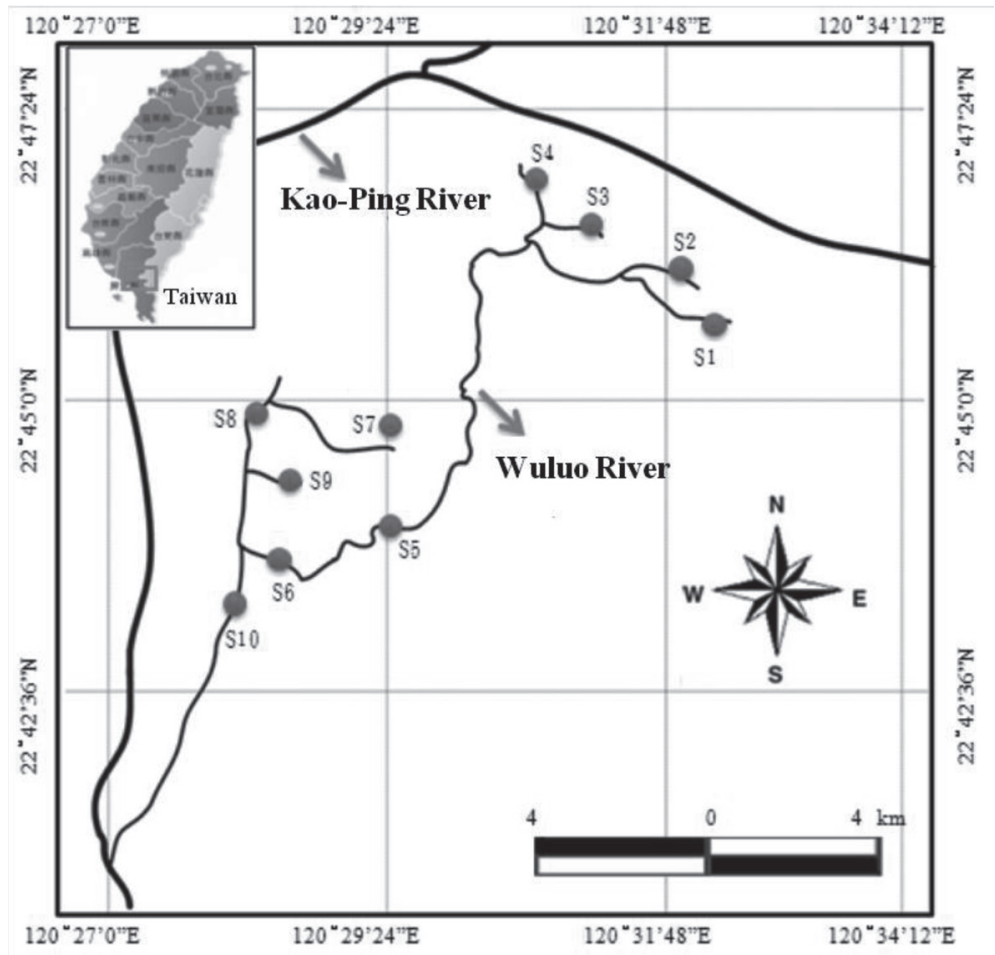

Fig. 1. Schematic of blood samples and groundwater sampling sites.

other HPLC-grade chemicals were purchased from Sigma Chemical Co. (St. Louis, MO, U.S.A.).

Sample collection: Groundwater samples were collected from 10 pig herds raised near the Wuluo River (Fig. 1). Two liters of groundwater were collected from each pig farm. For 5 of the 10 pig herds, blood samples $(n=10)$ were randomly collected from healthy 6-week-old piglets and sows. Blood samples were collected from the cranial vena cava and deposited into vacutainers (Becton Dickinson and Co., Franklin Lakes, NJ, U.S.A.). After clotting, the blood samples were centrifuged at $1,200 \mathrm{~g}$ for $10 \mathrm{~min}$. The serum was separated and stored at $-20^{\circ} \mathrm{C}$ prior to analysis.

Pretreatment of groundwater samples: The groundwater samples were immediately passed through $1.6 \mu \mathrm{m}$ and $0.45 \mu \mathrm{m}$ filters. To inhibit microbial degradation, the $\mathrm{pH}$ levels of the samples were adjusted to 2.0 by adding concentrated hydrochloric acid. The samples were stored at $4{ }^{\circ} \mathrm{C}$ for a maximum of one week prior to analysis. The extractions were performed according to a previously published method [13]. The extraction cartridges (Oasis ${ }^{\circledR}$ HLB, Waters, Milford, MA, U.S.A.) were preconditioned with $10 \mathrm{~m} l$ dichloromethane/methanol $(50: 50, \mathrm{v} / \mathrm{v})$ and $5 \mathrm{ml}$ methanol and were rinsed with $10 \mathrm{~m} l$ deionized water. The samples were then passed through a cartridge under a vacuum. The cartridges were washed with $10 \mathrm{~m} l$ deionized water and $0.4 \mathrm{~m} l$ methanol and were air dried under a vacuum for $30 \mathrm{~min}$. The sample extracts were eluted with $8 \mathrm{~m} l$ dichloromethane. The extracts were dried via evaporation under nitrogen at $40^{\circ} \mathrm{C}$ and reconstituted in $1 \mathrm{ml}$ acetonitrile/deionized water
$(50: 50, \mathrm{v} / \mathrm{v})$. The extracts were passed through a $0.22 \mu \mathrm{m}$ filter with a polyvinylidene difluoride (PVDF) membrane into sample tubes and analyzed using high-pressure liquid chromatography (HPLC) fluorescence.

Pretreatment of blood samples: The blood samples were pretreated according to a previously described method [15]. Subsequently, $1 \mathrm{~m} l$ serum was mixed with $200 \mu l$ potassium dihydrogen phosphate $(1 \mathrm{M})$ and $8 \mathrm{ml}$ methyl tertiary butyl ether. The supernatant was centrifuged at 3,000 rpm for $10 \mathrm{~min}$ and dried via evaporation under nitrogen at $30^{\circ} \mathrm{C}$. The extracts were reconstituted in $500 \mu l$ methanol, passed through a $0.22-\mu \mathrm{m}$ filter with a PVDF membrane and analyzed using HPLC fluorescence.

Chemical analyses: The APEO derivatives were analyzed using a HPLC unit (Waters 2695 separation module) equipped with a fluorescence detection system (Waters 2475 separations module). An XTerra RP18 column (4.6 $\times$ $250 \mathrm{~mm} \times 5 \mu \mathrm{m}$, Waters) and a Zorbax Eclipse XDB-C8 column $(4.6 \times 150 \mathrm{~mm} \times 5 \mu \mathrm{m}$, Agilent, Santa Clara, CA, U.S.A.) were used to analyze the groundwater samples and blood samples, respectively. The excitation wavelengths and emission wavelengths were $227 \mathrm{~nm}$ and $313 \mathrm{~nm}$, respectively. The mobile phase consisted of acetonitrile (A) and water (B). The following HPLC gradients were used for the groundwater samples: 0 to $6 \min -\mathrm{A}=70 \%$ and $\mathrm{B}=30 \%$; $6.8 \mathrm{~min}-\mathrm{A}=100 \%$ and $\mathrm{B}=0 \%$; and $16 \mathrm{~min}-\mathrm{A}=70 \%$ and $\mathrm{B}=30 \%$. The following HPLC gradients were used for the blood samples: 0 to $6 \mathrm{~min}-\mathrm{A}=60 \%$ and $\mathrm{B}=40 \% ; 6.2$ to $6.8 \mathrm{~min}-\mathrm{A}=100 \%$ and $\mathrm{B}=0 \%$; and 13 to $20 \mathrm{~min}-\mathrm{A}=60 \%$ 
Table 1. Standard curves and recovery percentages of NP, OP, $\mathrm{NP}_{1} \mathrm{EO}$ and $\mathrm{NP}_{2} \mathrm{EO}$

\begin{tabular}{lccc}
\hline Chemicals & Equation & $\begin{array}{c}\text { Correlation } \\
\text { Coefficient }(\mathrm{r})\end{array}$ & $\begin{array}{c}\text { Recovery } \\
\text { Percentage }(\%)\end{array}$ \\
\hline $\mathrm{NP}$ & $\mathrm{y}=39671 \times+1066$ & 0.999 & $95.7 \%$ \\
$\mathrm{OP}$ & $\mathrm{y}=428580 \times-324$ & 0.999 & $88.1 \%$ \\
$\mathrm{NP}_{1} \mathrm{EO}$ & $\mathrm{y}=319076 \times-735$ & 0.999 & $85.4 \%$ \\
$\mathrm{NP}_{2} \mathrm{EO}$ & $\mathrm{y}=279350 \times-584$ & 0.999 & $89.0 \%$ \\
\hline
\end{tabular}

NP: Nonylphenol, OP: Octylphenol, $\mathrm{NP}_{1} \mathrm{EO}$ : Nonylphenol monoethoxylate, $\mathrm{NP}_{2} \mathrm{EO}$ : Nonylphenol diethoxylate.

and $\mathrm{B}=40 \%$. A $20 \mu \mathrm{l}$ aliquot of each sample was injected for analysis. The flow rate was set to $500 \mu l$ per min.

Standard curves, recoveries and detection limits: Stock solutions of each test chemical (NP, OP, $\mathrm{NP}_{1} \mathrm{EO}$ and $\mathrm{NP}_{2} \mathrm{EO}$ ) were prepared by dissolving $500 \mathrm{mg}$ in $1 \mathrm{l}$ methanol. All stock solutions and mixtures were stored in the dark at $4{ }^{\circ} \mathrm{C}$. Working standard curves were prepared by diluting aliquots of the stock solutions in methanol. A recovery standard was added to the samples prior to extraction. The method detection limit (MDL) for the APEO derivatives in groundwater was $0.025 \mu \mathrm{g} / \mathrm{l}$. The MDLs for NP and OP in the blood samples were $1 \mu \mathrm{g} / l$ and $0.5 \mu \mathrm{g} / l$, respectively.

Statistical analysis: The data are described as the mean \pm standard deviation. The variation in the results among the groups was assessed using a $t$-test. The statistical significance was defined as $P$ value $<0.05$.

\section{RESULTS}

The standard curves generated for $\mathrm{NP}, \mathrm{OP}, \mathrm{NP}_{1} \mathrm{EO}$ and $\mathrm{NP}_{2} \mathrm{EO}$ were generally linear. The percent recoveries are listed in Table 1 . The minimum recovery for all chemicals was $85.4 \%$.

Table 2 lists the concentrations of four APEO derivatives- $\mathrm{NP}, \mathrm{NP}_{1} \mathrm{EO}, \mathrm{NP}_{2} \mathrm{EO}$ and $\mathrm{OP}$ - that were detected in the groundwater samples. A concentration of $0.043 \mu \mathrm{g} / l$ for NP was detected in only S6 sample. The majority of groundwater samples $(90 \%)$ contained $\mathrm{NP}_{1} \mathrm{EO}$ with an average concentration of $0.74 \pm 0.69 \mu \mathrm{g} / l$. $\mathrm{NP}_{2} \mathrm{EO}$ was observed in $70 \%$ of samples with an average concentration of $0.17 \pm$ $0.22 \mu \mathrm{g} / \mathrm{l}$. OP was detected in all samples with an average concentration of $0.26 \pm 0.23 \mu \mathrm{g} / l$.

The final products of APEO, NP and OP in the blood samples were analyzed. In all five pig herds, the concentration of NP varied between sows and piglets. The highest concentrations of NP that were detected in the blood samples from six-week-old piglets and sows were 12.00 and $56.94 \mu \mathrm{g} / \mathrm{l}$, respectively (Table 3 ). The concentration of OP, which was detected in four of the 5 pig herds, ranged from $<$ MDL to $566.32 \mu \mathrm{g} / l$. The highest OP concentrations in the blood samples of six-week-old piglets and sows were 275.58 and $566.32 \mu \mathrm{g} / l$, respectively. No significant differences between the OP concentrations of sows and those of piglets were identified (Table 4).
Table 2. Concentrations of APEO derivatives in groundwater collected from ten pig herds ${ }^{\text {a) }}$

\begin{tabular}{ccccc}
\hline Herds & $\mathrm{NP}$ & $\mathrm{NP}_{1} \mathrm{EO}$ & $\mathrm{NP}_{2} \mathrm{EO}$ & $\mathrm{OP}$ \\
\hline $\mathrm{S} 1$ & $<\mathrm{MDL}$ & 0.22 & $<\mathrm{MDL}$ & 0.34 \\
S2 & $<\mathrm{MDL}$ & 2.27 & 0.05 & 0.10 \\
S3 & $<\mathrm{MDL}$ & 0.55 & 0.06 & 0.05 \\
S4 & $<\mathrm{MDL}$ & $<\mathrm{MDL}$ & 0.21 & 0.12 \\
S5 & $<\mathrm{MDL}$ & 0.67 & 0.11 & 0.08 \\
S6 & 0.043 & 0.50 & 0.27 & 0.25 \\
S7 & $<\mathrm{MDL}$ & 0.24 & $<\mathrm{MDL}$ & 0.24 \\
S8 & $<\mathrm{MDL}$ & 1.63 & 0.69 & 0.44 \\
S9 & $<\mathrm{MDL}$ & 0.61 & $<\mathrm{MDL}$ & 0.17 \\
S10 & $<\mathrm{MDL}$ & 0.69 & 0.30 & 0.82 \\
\hline
\end{tabular}

a) Concentrations are expressed in $\mu \mathrm{g} / l$. NP: Nonylphenol, $\mathrm{NP}_{1} \mathrm{EO}$ : Nonylphenol monoethoxylates, $\mathrm{NP}_{2} \mathrm{EO}$ : Nonylphenol diethoxylates, OP: Octylphenol, MDL: Method detection limit.

\section{DISCUSSION}

The focus of this study was to determine the concentration of APEO derivatives in groundwater and blood samples collected from pig herds. APEO derivatives were instantly detected in the groundwater samples and the pig blood samples. Because groundwater is the main source of water for livestock and APEO derivatives are highly liposoluble and resistant to degradation, pigs are at risk of accumulating these pollutants by ingesting contaminated water.

Previous studies have shown that NP and OP primarily act as pseudoestrogens in vivo, which results in the feminization of exposed animals [5]. Rats exposed to 75 or $15 \mathrm{mg} \mathrm{NP} / \mathrm{kg}$ / day showed a significant reduction in the weight of the right epididymis [6]. APEO derivatives have been demonstrated to significantly influence the functions of the immune system and vital organs. It has also been established that NP and OP impair cytokine secretion in the mouse macrophage cell line RAW 264 after exposure of the cells to lipopolysaccharide $[5,17]$. NP and OP can suppress the Th1 pathway and enhance the Th2 cell pathway, which results in an imbalanced Th1/Th2 system [7]. NP is capable of inducing apoptosis in Jurkat cells and thymocytes by activating caspase- 8 and caspase-3, respectively; it also causes mitochondrial depolarization [16]. OP has been shown to bind to estrogen receptors and modulate the activities of the mouse macrophage cell line [10]. The results of a canine study indicated that the oral administration of APEO mixtures at $40 \mathrm{mg} / \mathrm{kg} /$ day caused cardiotoxicity [12]. However, minimal information about the effects of alkylphenol accumulation in pigs is available. Additional research is needed to evaluate the effects of APEO on the physical, pathological and immunological functions of pigs.

An analysis of pork products revealed NP concentrations and $\mathrm{OP}$ concentrations of $47.3 \pm 41.4$ and $3.0 \pm 1.4 \mathrm{ng} / \mathrm{g}$ (wet weight), respectively [8], whereas higher concentrations of NP and OP were detected in the pig blood measured in this study. Because pig blood is a popular food in Taiwan and other Asian countries, the accumulation of NP and OP may result in adverse effects in humans who regularly consume 
Table 3. Nonylphenol concentrations detected in blood samples collected from six-week-old piglets and sows in five herds

\begin{tabular}{ccccc}
\hline Herds & Age & $\begin{array}{c}\text { Sampling number/ } \\
\text { Number detected }\end{array}$ & Mean $\pm \mathrm{SD}(\mu \mathrm{g} / l)$ & Range $(\mu \mathrm{g} / l)$ \\
\hline S1 & Piglet & $10 / 1$ & 1.32 & 1.32 \\
& Sow & $10 / 1$ & 8.88 & 8.88 \\
S2 & Piglet & $10 / 8$ & $1.21 \pm 0.20$ & $1.02-1.32$ \\
& Sow & $10 / 7$ & $1.70 \pm 0.45$ & $1.12-2.38$ \\
S3 & Piglet & $10 / 3$ & $1.11 \pm 0.09$ & $1.02-12.00$ \\
& Sow & $7 / 6^{\mathrm{a}}$ & $16.57 \pm 20.29$ & $3.98-56.94$ \\
S5 & Piglet & $10 / 8$ & $1.31 \pm 0.26$ & $1.06-1.74$ \\
& Sow & $10 / 8$ & $1.51 \pm 0.53$ & $1.20-2.86$ \\
S6 & Piglet & $10 / 6$ & $1.34 \pm 0.10$ & $1.16-1.42$ \\
& Sow & $10 / 2$ & $1.61 \pm 0.38$ & $1.34-1.88$ \\
\hline
\end{tabular}

a) Only 7 sows available for blood sample collection during sampling period.

Table 4. Octylphenol concentrations detected in blood samples collected from six-week-old piglets and sows in five herds

\begin{tabular}{ccccc}
\hline Herds & Age & $\begin{array}{c}\text { Sampling number/ } \\
\text { Number detected }\end{array}$ & Mean $\pm \mathrm{SD}(\mu \mathrm{g} / l)$ & Range $(\mu \mathrm{g} / l)$ \\
\hline S1 & Piglet & $10 / 3$ & $145.56 \pm 113.81$ & $64.00-275.58$ \\
& Sow & $10 / 5$ & $62.38 \pm 65.87$ & $15.60-166.88$ \\
S2 & Piglet & $10 / 0$ & $<\mathrm{MDL}$ & - \\
& Sow & $10 / 0$ & $<\mathrm{MDL}$ & - \\
S3 & Piglet & $10 / 1$ & 15.04 & 15.04 \\
& Sow & $7 / 0^{\mathrm{a})}$ & $<\mathrm{MDL}$ & - \\
S5 & Piglet & $10 / 0$ & $<\mathrm{MDL}$ & - \\
& Sow & $10 / 1$ & 566.32 & 566.32 \\
S6 & Piglet & $10 / 2$ & $15.61 \pm 12.94$ & $6.46-24.76$ \\
& Sow & $10 / 5$ & $62.90 \pm 108.91$ & $3.26-256.36$ \\
\hline
\end{tabular}

a) Only 7 sows available for blood sample collection during sampling period.

food containing pig blood.

A total of 18 rivers in Taiwan have been reported to be contaminated with NP with concentrations in the range of $<0.01$ to $5.1 \mu \mathrm{g} / \mathrm{l}[1]$. More than $90 \%$ of the samples obtained from these rivers exceeded the predicted no-effect concentration for NP $(0.33$ to $0.60 \mu \mathrm{g} / l)$ (Ministry of the Environment, 2001). According to our data, NP concentrations in groundwater are substantially lower than the NP concentrations in rivers in Taiwan. The maximum concentrations of $\mathrm{NP}, \mathrm{NP}_{1} \mathrm{EO}, \mathrm{NP}_{2} \mathrm{EO}$ and $\mathrm{OP}$ detected in Australian groundwater were $1.50,0.15,0.15$ and $0.04 \mu \mathrm{g} / l$, respectively [4]. With the exception of NP, all reported concentrations of $\mathrm{NP}_{1} \mathrm{EO}, \mathrm{NP}_{2} \mathrm{EO}$ and $\mathrm{OP}$ in the groundwater in Australia were lower than those in the groundwater in Taiwan. Groundwater contamination by these substances is a critical public health issue. Although the Taiwanese government banned the use of NPEO in detergents in 2007, groundwater contamination by endocrine-disrupting chemicals remains unknown. Additional studies are required to investigate the variation in groundwater contaminants over time and the potential risk.

ACKNOWLEDGMENT. We thank Dr. Paul Su for assist samples collection.

\section{REFERENCES}

1. Cheng, C. Y., Wu, C. Y., Wang, C. H. and Ding, W. H. 2006. Determination and distribution characteristics of degradation products of nonylphenol polyethoxylates in the rivers of Taiwan. Chemosphere 65: 2275-2281. [Medline] [CrossRef]

2. Eskenazi, B., Mocarelli, P., Warner, M., Samuels, S., Vercellini, P., Olive, D., Needham, L., Patterson, D. and Brambilla, P. 2000. Seveso Women's Health Study: a study of the effects of 2,3,7,8-tetrachlorodibenzo-p-dioxin on reproductive health. Chemosphere 40: 1247-1253. [Medline] [CrossRef]

3. Giger, W., Brunner, P. H. and Schaffner, C. 1984. 4-Nonylphenol in sewage sludge: accumulation of toxic metabolites from nonionic surfactants. Science 225: 623-625. [Medline] [CrossRef]

4. Hohenblum, P., Gans, O., Moche, W., Scharf, S. and Lorbeer, G. 2004. Monitoring of selected estrogenic hormones and industrial chemicals in groundwaters and surface waters in Austria. Sci. Total Environ. 333: 185-193. [Medline] [CrossRef]

5. Hong, C. C., Shimomura-Shimizu, M., Muroi, M. and Tanamoto, K. 2004. Effect of endocrine disrupting chemicals on lipopolysaccharide-induced tumor necrosis factor-alpha and nitric oxide production by mouse macrophages. Biol. Pharm. Bull. 27: 1136-1139. [Medline] [CrossRef]

6. Hossaini, A., Dalgaard, M., Vinggaard, A. M., Frandsen, H. and Larsen, J. J. 2001. In utero reproductive study in rats exposed to nonylphenol. Reprod. Toxicol. 15: 537-543. [Medline] [CrossRef]

7. Iwata, M., Eshima, Y., Kagechika, H. and Miyaura, H. 2004. The 
endocrine disruptors nonylphenol and octylphenol exert direct effects on T cells to suppress Th1 development and enhance Th2 development. Immunol. Lett. 94: 135-139. [Medline] [CrossRef]

8. Lu, Y. Y., Chen, M. L., Sung, F. C., Wang, P. S. and Mao, I. F. 2007. Daily intake of 4-nonylphenol in Taiwanese. Environ. Int. 33: 903-910. [Medline] [CrossRef]

9. Porte, C., Biosca, X., Pastor, D., Sole, M. and Albaiges, J. 2000. The aegean sea oil spill. 2. temporal study of the hydrocarbons accumulation in bivalves. Environ. Sci. Technol. 34: 5067-5075. [CrossRef]

10. Ruh, M. F., Bi, Y., Cox, L., Berk, D., Howlett, A. C. and Bellone, C. J. 1998. Effect of environmental estrogens on IL-1beta promoter activity in a macrophage cell line. Endocrine 9: 207-211. [Medline] [CrossRef]

11. Safe, S., Wang, F., Porter, W., Duan, R. and McDougal, A. 1998. Ah receptor agonists as endocrine disruptors: antiestrogenic activity and mechanisms. Toxicol. Lett. 102-103: 343-347. [Medline] [CrossRef]

12. Smyth, H. F. Jr. and Calandra, J. C. 1969. Toxicologic studies of alkylphenol polyoxyethylene surfactants. Toxicol. Appl. Pharmacol. 14: 315-334. [Medline] [CrossRef]
13. Wang, J., Pan, H., Liu, Z. and Ge, F. 2009. Ultra-high-pressure liquid chromatography-tandem mass spectrometry method for the determination of alkylphenols in soil. J. Chromatogr. A 1216: 2499-2503. [Medline] [CrossRef]

14. White, R., Jobling, S., Hoare, S. A., Sumpter, J. P. and Parker, M. G. 1994. Environmentally persistent alkylphenolic compounds are estrogenic. Endocrinology 135: 175-182. [Medline]

15. Xiao, Q., Li, Y., Ouyang, H., Xu, P. and Wu, D. 2006. Highperformance liquid chromatographic analysis of bisphenol A and 4-nonylphenol in serum, liver and testis tissues after oral administration to rats and its application to toxicokinetic study. $J$. Chromatogr. B Analyt. Technol. Biomed. Life Sci. 830: 322-329. [Medline] [CrossRef]

16. Yao, G., Ling, L., Luan, J., Ye, D. and Zhu, P. 2007. Nonylphenol induces apoptosis of Jurkat cells by a caspase- 8 dependent mechanism. Int. Immunopharmacol. 7: 444-453. [Medline] [CrossRef]

17. Yurino, H., Ishikawa, S., Sato, T., Akadegawa, K., Ito, T., Ueha, S., Inadera, H. and Matsushima, K. 2004. Endocrine disruptors (environmental estrogens) enhance autoantibody production by B1 cells. Toxicol. Sci. 81: 139-147. [Medline] [CrossRef] 